\title{
The Podocyte as a Therapeutic Target in Proteinuric Kidney Disease
}

\author{
Kristin Meliambro', John Cijiang $\mathrm{He}^{1,2}$ and Kirk N Campbell ${ }^{1 *}$
}

${ }^{1}$ Division of Nephrology, Icahn School of Medicine at Mount Sinai, New York, USA

${ }^{2}$ Department of Pharmacology and Systems Therapeutics, Icahn School of Medicine at Mount Sinai, New York, USA

\begin{abstract}
Kidney podocytes are highly differentiated cells with a complex cellular morphology. They are located inside the glomerulus, a corpuscle of capillaries through which blood is filtered hydrostatically through a high-volume/highdiscrimination filter. Neighboring podocyte Foot Processes (FP) is connected by a specialized cell-cell junction, the Slit Diaphragm (SD), which represents the main size selective filtration barrier in the kidney. The podocyte is an attractive cell for drug targeting due largely to its presence on the epithelial surface of one of the best vascularized organs in the body. Podocytes are exposed to 180 liters of filtered water and solutes each day, with the glomerular basement membrane and fenestrated glomerular endothelium not likely to be obstacles to small molecule passage. Though no podocyte-specific drugs are presently available, clinical nephrology has taken advantage of the pleitropic effects of a diverse array of therapeutic agents to treat glomerular disease. Glucocorticoids, retinoic acid, cyclosporine, abatacept, $\mathrm{ACTH}$, thiazolidinedione, angiotensin converting enzyme inhibitors and rituximab have been successfully repurposed from other clinical indications to treat protein uric kidney disease. By different mechanisms these agents all nonspecifically target podocytes to promote their survival under disease conditions. This review summarizes the currently understood mechanistic basis for their use.
\end{abstract}

Keywords: Podocytes; Tumor necrosis factor; Glomerulosclerosis

\section{Introduction}

All forms of nephrotic syndrome are characterized by abnormalities in podocytes including retraction (effacement) of podocyte FP and/ or molecular reorganization of the SD [1]. Foot process effacement requires a precise interplay of multiple cellular functions including structural alterations of the cytoskeleton, movement of FP over the glomerular basement membrane, and reconstruction of the SD [2]. The discovery of several novel podocyte proteins and their mutation analysis including nephrin [3], CD2AP [4,5], a-actinin-4 [6], podocin [7], TRPC6 [8,9], neph1 [10] and PLCe1 [11] has shed light on the pathogenesis of proteinuria and emphasized the critical role of the podocyte and the SD in maintaining the integrity and function of the glomerular filtration barrier. Recently, mutations encoding INF2 [12], a member of the formin family of actin-regulating proteins, have been identified as a major cause of autosomal dominant Focal Segmental Glomerulosclerosis (FSGS) [13]. Clear clinical correlations between a reduction in podocyte number and proteinuria have been identified. A reduction in podocyte number beyond a critical threshold is sufficient to cause glomerular disease progression in experimental models $[14,15]$. In human disease, podocyte depletion contributes to the progression of diabetic nephropathy in type I and type II diabetes mellitus [16-18]. Podocyte loss also correlates closely with the degree of proteinuria, glomerulosclerosis and renal dysfunction in patients with IgA nephropathy [19]. These and other findings have established podocytes as the key target cell in glomerular disease progression. Though no podocyte-specific drugs are currently commercially available, many agents originally developed for other clinical indications are used to treat glomerular disease and act directly on the podocyte to preserve their structural integrity. Here we will summarize the current knowledge regarding their mechanism of action on podocytes. This review is not all-inclusive and does not contain a discussion of novel or potential therapeutic targets. The focus is on agents currently in clinical use.

\section{ACE-inhibitor/ARB Therapy}

Glomerular capillary hypertension induces podocyte injury and subsequent podocyte loss with glomerulosclerosis then leads to increased pressure gradients across capillary walls in remaining functional nephrons, perpetuating a deleterious cycle of further podocyte damage [20]. Angiotensin II is an important regulator of glomerular capillary pressure through its effects on afferent and efferent glomerular arterioles. Inhibition of angiotensin II production and/or receptor binding has been shown to ameliorate the progression of kidney diseases characterized by elevated glomerular capillary pressure [21]. Apart from hemodynamic effects there is evidence that locally produced angiotensin II in the kidneys promote release of cytokines and chemokines such transforming growth factor (TGF)beta1, osteopontin, Tumor Necrosis Factor (TNF)-alpha, secreted protein acidic and rich in cysteine (SPARC), and RANTES (regulated on activation normal T-cell expression and secreted) that can induce tubule interstitial fibrosis and inflammation, stimulate monocytes/ macrophages infiltration, promote cellular proliferation, and stimulate apoptosis [22]. The suggestion of a direct effect of angiotensin II on podocytes in particular has been put forth by several authors. Angiotensin II induces reorganization of the actin cytoskeleton and increases intracellular cAMP in cultured glomerular epithelial cells [23]. ACE inhibition prevents glomerular redistribution of the tight junction protein Zona Occluden-s1 (ZO-1), a component of the slit diaphragm, which is associated with the development of proteinuria in MWF rats [24]. In experimental models of diabetic nephropathy, treatment with the ACE-inhibitor perindopril attenuates foot process broadening and restores expression of the slit diaphragm protein nephrin, which is down regulated under disease conditions [25,26]. Given these findings and previous findings that mechanical stress inhibits leads to rearrangement of the podocyte actin cytoskeleton [27], one study evaluated the effects of mechanical strain on angiotensin II

*Corresponding author: Kirk N Campbell, Division of Nephrology, Icahn School of Medicine at Mount Sinai, Box 1243, One Gustave L Levy Place, NY 10029, USA Tel: (212) 241-6271; Fax: (212) 987-0389; E-mail: kirk.campbell@mssm.edu

Received October 29, 2013; Accepted November 26, 2013; Published November 29, 2013

Citation: Meliambro K, He JC, Campbell KN (2013) The Podocyte as a Therapeutic Target in Proteinuric Kidney Disease. J Nephrol Ther 3: 143. doi:10.4172/21610959.1000143

Copyright: (c) 2013 Meliambro K, et al. This is an open-access article distributed under the terms of the Creative Commons Attribution License, which permits unrestricted use, distribution, and reproduction in any medium, provided the original author and source are credited. 
production and subsequent podocyte injury [28]. Immortalized human podocytes subjected to cyclical stretch had increased angiotensin II production, which was not diminished in the setting of pre- incubation with an ACE-inhibitor, and increased expression of the Angiotensin 1 Receptor (AT1R). Overexpression of AT1R was also observed in the remnant kidney model in the rat that is associated with glomerular capillary hypertension, as revealed by immune staining. Mechanical strain induced apoptosis of podocytes in a seemingly AT1Rdependent fashion, as this effect was duplicated following exogenous administration of angiotensin II to podocytes and was conversely diminished following treatment with the AT1R antagonist valsartan [28]. The same authors showed that hyperglycemia may contribute to increased angiotensin II production in cultured podocytes by upregulation of renin activity, offering an additional stimulus for activation of the renin-angiotensin system in diabetic kidney disease [29]. Both papers suggest that the therapeutic benefit of angiotensin blockade in chronic renal disease stems not only from the reduction in glomerular capillary pressure but also from protection of podocytes against apoptosis and actin cytoskeletal rearrangement that is at least in part induced by mechanical stress. However, given that ACEinhibitors were not able to mitigate the effects of either mechanical strain or hyperglycemia on angiotensin production, there may be an ACE-independent pathway primarily responsible for generation of angiotensin II from angiotensin I in podocytes. Angiotensin II has been reported to increase free cytosolic calcium in podocytes via release from intracellular stores as well as entry from the extracellular compartment, which may be mediated by TRPC6 [30,31]. Indeed, mutations in TRPC6 that increases its responsiveness to angiotensin II have been identified in familial forms of FSGS [9]. Intracellular calcium accumulation can lead to activation of Calmodulin-dependent protein kinase (CaMK) II across different species [32], and then CaMK II activates a downstream signaling pathway mediated by the transcription factor cAMP response element (CRE)-binding protein (CREB), which is involved in multiple physiological processes [33]. CaMKs/CREB activation is accompanied by up-regulation of Wnt. Activation of Wnt/ $\beta$-catenin signaling, an evolutionarily conserved signaling cascade, can trigger podocyte injury and dedifferentiation [34]. Angiotensin II was observed to activate CaMK signaling in cat and rat myocytes [35], and it was recently demonstrated that angiotensin also mediates phosphorylation of CaMK and CREB in cultured podocytes [36]. Angiotensin II infusion ultimately upregulates Wnt expression and activated $\beta$-catenin via CaMK/CREB signaling pathway, which leads to subsequent podocyte injury in vitro and in vivo mouse models [36]. Inhibition of the CaMK/CREB and $\mathrm{Wnt} / \beta$-catenin signaling pathways ameliorates angiotensin-II-induced podocyte damage in vitro and in vivo. TGF- $\beta$ may represent the link between angiotensin II and Wnt/ $\beta$-catenin signaling as angiotensin II is known to up regulate TGF- $\beta$ expression [37], and TGF- $\beta$ separately has been shown to increase Wnt expression, $\beta$-catenin activation, and expression of $\mathrm{Wnt} / \beta$-catenin downstream target genes [38]. In summary the effects of angiotensin II on various intracellular signaling pathways and demonstrated success of some targeted angiotensin inhibitors in amelioration of podocyte damage represents another potential area for therapeutic development.

\section{Glucocorticoids}

Glucocorticoids have been the mainstay of treatment for nephrotic syndrome for nearly 60 years, despite limited understanding of both the pathogenesis of nephrotic syndrome and the mechanistic basis for their use. It was suggested in the 1970s that minimal change disease may be an autoimmune disorder derived from secretion of a "basement membrane toxin" by a clonal population of T-lymphocytes that enhanced basement membrane permeability, thus explaining response to the immunosuppressive effects of glucocorticoids and their preferential depletion of T-lymphocytes over B-lymphocytes [39]. Though numerous candidate permeability factors have been proposed such as hemopexin [40,41], angiopoietin-like-4 [42] and vascular permeability factor [43] in minimal change disease, and cardiotrophinlike cytokine-1 [44] and Soluble Urokinase Receptor (suPAR) in FSGS [45], further investigational and confirmatory studies are needed.

Recently, studies have focused on the potential targeted actions of glucocorticoid treatment on podocyte structure, function, and cell survival. This shift in investigational focus follows the demonstration of the presence of glucocorticoid receptors in podocytes, as well as glomerular cells, parietal epithelial cells, endothelial cells, and mesangial cells, via immunoblot and immunohistochemical studies with glucocorticoid receptor nuclear translocation shown in response to dexamethasone treatment [46]. Glucocorticoids increase the stability of actin filaments and induce expression of cytoskeletal-associated kinases that promote microfilament assembly $[47,48]$. Dexamethasone treatment in vitro protects podocytes from Puromycin Amino Nucleoside (PAN) injury by inhibiting actin filament disruption and increasing RhoA expression [49]. The glucocorticoid-podocyte relationship is specific, as mesangial cells and fibroblasts are not similarly protected from PAN injury even at higher concentrations of dexamethasone, and pre-treatment with alternate steroid hormones do not mitigate the deleterious effects of PAN on podocytes [49]. In addition to the protective effect on the actin cytoskeleton dexamethasone also protects podocytes from PAN-induced apoptosis. Dexamethasone abrogates p53 and pro-apoptotic Bax expression associated with PAN treatment. Dexamethasone also inhibits the nuclear translocation of apoptosis-inducing factor after PAN treatment [50].

\section{Cyclosporine}

Cyclosporine has long been shown to reduce proteinuria in nephrotic syndrome secondary to FSGS and minimal change disease [51-53]. Cyclosporine is an inhibitor of the serine/threonine kinase calcineurin, which regulates NFAT (nuclear factor of activated T cells) signaling, and the immunosuppressive actions of cyclosporine are attributed to NFAT inhibition in T cells [54]. Since some forms of nephrotic syndrome are thought to have immunologic origins secondary to T-cell dysfunction leading to podocyte injury, it was initially believed that the therapeutic effect of cyclosporine was primarily mediated by NFAT inhibition [55]. However, the benefit of cyclosporine in non-immunologic forms of nephrotic syndrome such as Alport's disease [56] suggests a non-immunologic basis for calcineurin inhibitor action. It has been demonstrated that synaptopodin, a podocyte actin-bundling protein $[57,58]$ colocalizes with calcineurin and is a target of calcineurin signaling [59]. Calcineurin dephosphorylates synaptopodin at its 14-3-3 binding motifs, thereby making synaptopodin more susceptible to Cathepsin L mediated degradation [59]. Transgenic mice overexpressing calcineurin have reduced levels of synaptopodin as well as RhoA and have significant proteinuria [59]. Calcineurin is also activated in heart tissue by the canonical transient receptor potential- 6 (TRPC6) [60], which is a component of the glomerular slit diaphragm and a disease gene in FSGS $[8,9]$. It has been hypothesized that calcium influx via TRPC6 may activate calcineurin, leading to loss of synaptopodin in podocytes to produce nephrotic syndrome phenotype. This is supported by the finding that TRPC6 overexpression leads to loss of actin stress fibers similar to synaptopodin gene deletion and development of proteinuria $[58,61]$. Overall these results elucidate a new mechanism of podocyte 
injury due to down regulation of synaptopodin via calcineurin, which can be mitigated by cyclosporine and hopefully can be translated to the development of new therapeutic agents in the future.

\section{Rituximab}

Rituximab is a monoclonal antibody directed against the CD20 receptor on B- lymphocytes that has been used to acute allograft rejection, recurrent FSGS post kidney-transplantation [62], and ANCAassociated glomerulonephritis [63], as well as steroid-dependent nephrotic syndrome in adults [64] and children [65]. Rituximab may potentially cross-react with sphingomyelin phosphodiesterase acid-like $3 \mathrm{~b}$ protein (SMPDL-3b) [66] and may regulate acid sphingomyelinase (ASMase) activity in raft microdomains [67], which are central organizers of cellular receptors and signaling molecules [68], as was observed in lymphoma cells. A recent study explored the hypothesis that Rituximab could control the actin cytoskeleton remodeling process in podocytes via stabilization of sphingolipid-related enzymes [69]. First, CD20 was found to be absent in podocytes from normal human kidney sections and post reperfusion biopsies from patients with FSGS, while rituximab was found to bind SMPDL-3b in podocytes from normal human kidney sections and cultured human podocytes, supporting a CD20-independent effector pathway for rituximab in podocytes. SMPDL-3b protein expression was decreased in post-reperfusion biopsies from patients who later developed recurrent FSGS posttransplant [69]. When human podocytes were cultured in the presence of sera collected pre-transplant from these patients, there was similarly found to be downregulation of SMPDL-3b and ASMase protein levels and reduced ASMase activity, but this was prevented by rituximab treatment [69]. Actin stress fibers were disrupted in podocytes cultured in the presence of recurrent FSGS patient sera, and there was a positive correlation between the loss of stress fibers and the urinary protein/creatinine ratio post-transplantation. Both pre-treatment with rituximab and SMPDL-3b overexpression in these podocytes partially reduced this stress fiber disruption, suggesting a sphingolipiddependent effect of recurrent FSGS sera on the actin cytoskeleton which is opposed by rituximab [69]. This is further supported by the observation that rituximab treatment did not prevent the more pronounced stress fiber disruption or the increased level of apoptosis seen in SMPDL-3b knockdown cells after exposure to recurrent FSGS sera. In their conclusion, the authors highlight that the potential role of sphingolipid metabolism in glomerular injury [69]. This is supported by observed glomerular pathology in patients afflicted by the genetic disorder Niemann- Pick disease, in which sphingomyelin accumulates due to lack to lack of ASMase activity [70]. There is therefore some evidence for targeted protective action of rituximab on the podocyte actin cytoskeleton via preservation of sphingomyelin-related enzymes which can contribute to preservation of the glomerular filtration barrier and reduction of proteinuria following podocyte injury.

\section{Retinoic Acid}

A hallmark feature of HIV-Associated Nephropathy (HIVAN), which appears histologically as collapsing focal segmental glomerulosclerosis [71], is the proliferation and dedifferentiation of podocytes as seen in HIV transgenic mice [72] and podocytes infected with HIV-1 in vitro [73]. These phenotypic changes are primarily attributed to the HIV nef gene [74], which was shown to increase activity of Src kinase and phosphorylation of signal transducer and activator of transcription 3 (Stat3) and activate the Ras-c-Raf-MAPK1,2 pathway in infected podocytes [75]. Retinoids, derivatives of vitamin A which are produced at high levels in the kidneys [76], regulate cell proliferation, differentiation, and apoptosis. The cellular effects of retinoids are mediated via binding to their nuclear receptors, Retinoic Acid Receptors (RAR) and retinoid X receptors (RXR), which leads to gene transcription [77] and also via direct activation of cytosolic signaling molecules such as MAPK [78] and protein kinase C [79]. In addition to their role in treatment of malignancies such as acute myeloblastic leukemia, retinoids first showed promise as therapy for glomerular disease in animal studies as they were found to reduce glomerular damage and albuminuria in rat models of mesangioproliferative glomerulonephritis [80], improve foot process effacement and diminish proteinuria in PAN models of nephrosis [81], and protect against the development of glomerulonephritis in mouse models of lupus nephritis [82]. Recently, the effects of retinoid therapy against podocyte proliferation and dedifferentiation underlying HIVAN have been investigated. AtRA (All-trans-retinoic acid) has been demonstrated to reduce proliferation of both control and HIV-1 infected podocytes in a reversible, apoptosis-independent manner and inhibit contactindependent growth of podocytes induced by HIV-1 infection [83]. In HIV-1 infected cells, AtRA inhibits cell proliferation by inducing arrest in phase G1 of the cell cycle, likely via downregulation of expression of cell cycle proteins cyclin A and cyclin E. AtRA-induced differentiation of podocytes is suggested by the detection of increased mRNA levels of markers of podocyte differentiation including WT-1, synaptopodin, nephrin, and podocin following AtRA treatment of HIV-1 infected podocytes. The in vitro findings of this study were replicated in vivo as treatment of HIV-1 transgenic mice (Tg26) with AtRA led to reduction of proteinuria and glomerulosclerosis compared with untreated $\mathrm{Tg} 26$ mice [83]. Activation of the cAMP/PKA pathway has been proposed to be the likely mechanism underlying AtRA's reversal of HIV-1induced proliferation and dedifferentiation. Treatment of podocytes with a stimulator of adenylyl cyclase and cAMP analogue similarly inhibits proliferation and restored expression of synaptopodin on HIV-1 infected podocytes, whereas a competitor of endogenous cAMP diminishes these effects. These results have therapeutic significance as induction of the CAMP- PKA pathway has been shown to regulate the actin cytoskeleton assembly and morphology of podocytes such that glomerular permeability is reduced [84].

The demonstrated therapeutic effects of retinoids on HIV-1 infected podocytes in vitro and in experimental animal models of HIVAN present exciting new possibilities for future treatment of HIVAN, particularly in those patients who do not respond well to antiretroviral agents alone. An ongoing phase II clinical trial will investigate the use of AtRA to treat patients with steroid-resistant FSGS, minimal change disease, and collapsing glomerulopathy. Given that the side effect profile of AtRA is thought to be mediated mostly through the RARy receptors [85] a recent study [86] evaluated the effects of Am580, a specific RARa agonist that causes fewer side effects than AtRA [87], on Tg26 mice. Similar to the previously reported in vitro findings, treatment with Am580 prevented kidney hypertrophy, reduced proteinuria, and improved renal function. Similar to AtRA, Am580 inhibits podocyte proliferation and restored expression of the podocyte differentiation markers synaptopodin, nephrin, and WT-1. RARa knockout Tg26 mice have more severe podocyte injury and proteinuria than Tg26 littermates, which is not ameliorated by Am 580 treatment. This suggests that RAR $\alpha$ mediates an endogenous nephroprotective pathway. Another recent study explored the development of the novel RARa agonist BD4, a derivative of Am580 containing boronic acid, which was found to bind to RARa in podocytes with both higher affinity and lower toxicity than AtRA and AM580 [88]. Similar to AtRA and AM580, BD4 treatment induces the expression of differentiation markers in cultured podocytes and improves kidney injury and proteinuria in $\mathrm{Tg} 26$ mice. Though the full side effect profile of BD4 
is unknown, the results suggest that development and investigation of additional RARa agonists is a promising direction for future HIVAN therapies.

\section{Thiazolidinediones}

The thiazolidinedione class of antidiabetic agents includes the drugs pioglitazone and rosiglitazone which are agonists of the peroxisome proliferator-activated receptors $\gamma(\operatorname{PPAR} \gamma)$. PPAR $\gamma$ s are ligand-activated transcription factors of the nuclear hormone receptor superfamily that are involved in adipogenesis, glucose homeostasis, inflammatory responses, and apoptosis [89]. In addition to their glucose regulatory effects, thiazolidinediones have been shown to reduce podocyte injury, albuminuria, and proteinuria in animal models of nondiabetic and diabetic nephropathy as well as in human diabetic patients [90-92]. Pioglitazone ameliorates the development of PAN-induced glomerulosclerosis in vivo [93] and reduces podocyte apoptosis and necrosis in vitro [94]. Rosiglitazone attenuates the development of proteinuria and glomerulosclerosis in doxorubicininduced focal segmental glomerulosclerosis in rats [95]. Pioglitazone and rosiglitazone protect cultured podocytes from PAN-induced injury, though to a lesser extent than dexamethasone alone, and combination of thiazolidinediones with dexamethasone improved cell viability beyond that attained with either drug treatment alone [96]. Similar to glucocorticoids, thiazolidinediones protect actin filaments against disruption from PAN [96]. This study also adds to existing evidence that thiazolidinediones may affect PPAR $\gamma$ - independent pathways. Rosiglitazone in particular was shown to decrease activation of MAPKs, which have been known to produce podocyte injury and have been implicated in the pathogenesis of several in vivo models of renal disease [97].

\section{ACTH}

Adrenocorticotrophic Hormone (ACTH), a melanocortin polypeptide hormone endogenously produced by the anterior pituitary that stimulates cortisol production by the adrenal cortex [98] was initially used to treated childhood nephrotic syndrome in the $1950 \mathrm{~s}$ and 1960s in lieu of steroids [99]. The use of ACTH for nephrotic syndrome subsequently declined over the following decades until it was unexpectedly observed to reduce albuminuria and increase estimated GFR in patients with idiopathic nephrotic syndrome [100]. A recent randomized controlled study further showed that similar rates of remission and proteinuria reduction were obtained in patients with biopsy-proven idiopathic membranous nephrotic syndrome following one year of therapy with synthetic ACTH as compared with a six month regimen of methylprednisolone plus a cytotoxic agent (cyclophosphamide or chlorambucil) after a median follow up period of 24 months [101]. The observation that ACTH is an effective treatment option in steroid-resistant nephrosis [102] suggests that this hormone mediates its antiproteinuric effects by an independent mechanism from its steroidogenic actions, which is the focus of ongoing investigation. The identification of Melanocortin 1 Receptor (MC1R) expression in human podocytes [103], and the ability of a specific MC1R agonist to reduce glomerular injury in experimental Heyman nephritis [103], should help define the mechanism of action of synthetic ACTH used in Europe and the Acthar form available in the US.

\section{Abatacept}

Abatacept (CTLA-4-Ig) is an inhibitor of the T-cell costimulatory molecule B7-1 (CD80) that is currently approved for the treatment of rheumatoid arthritis [104]. Increased B7-1 expression in podocytes has been demonstrated in experimental mouse models of nephrotic syndrome and correlates with the severity of human lupus nephritis [105]. A recently published study demonstrated B7-1 immunostaining in recurrent FSGS post- transplantation and one patient with steroidresistant primary FSGS in a native kidney [106]. These five patients received Abetacept with subsequent improvement in proteinuria and renal function constituting complete or partial remissions in all [106]. In vitro studies demonstrated that B7-1 disrupts activation of $\beta-1$ integrin by competing with talin for $\beta-1$ integrin binding. In vitro, a proposed mechanism for the anti-proteinuric effect of Abatacept was identified in its ability to inhibit B7-1 induced podocyte migration and restoration of $\beta-1$ integrin activation in B7-1 expressing podocytes [106]. Subsequent clinical trials will be needed to fully explore the clinical utility of Abatacept in B7-1 positive glomerular disease.

\section{Conclusion}

The common etiology of nephrotic syndrome is podocyte injury and loss with associated actin cytoskeletal disruption and foot process effacement. There is significant evidence that currently available treatment modalities, irrespective of the intent when they were developed, indeed actively regulate the survival, differentiation, structural regulation, and cell signaling of podocytes. These factors affirm their place among recommended drug regimens for proteinuric kidney disease. Increased understanding of the signaling pathways underlying podocyte loss will enhance the pipeline of therapeutic targets in the development of podocyte-specific drugs. This will reduce the side effects patients are exposed to from long-term use of nonspecific and systemic immunosuppressive agents.

\section{References}

1. Asanuma K, Mundel $P(2003)$ The role of podocytes in glomerular pathobiology. Clin Exp Nephrol 7: 255-259.

2. Mundel P, Shankland SJ (2002) Podocyte biology and response to injury. J Am Soc Nephrol 13: 3005-3015.

3. Kestilä M, Lenkkeri U, Männikkö M, Lamerdin J, McCready $P$, et al. (1998) Positionally cloned gene for a novel glomerular protein--nephrin--is mutated in congenital nephrotic syndrome. Mol Cell 1: 575-582.

4. Kim JM, Wu H, Green G, Winkler CA, Kopp JB, et al. (2003) CD2-Â-associated protein haplo insufficiency is linked to glomerular disease susceptibility. Science 300: 1298-1300.

5. Shih NY, Li J, Karpitskii V, Nguyen A, Dustin ML, et al. (1999) Congenital nephrotic syndrome in mice lacking CD2-associated protein. Science 286: 312 315 .

6. Kaplan JM, Kim SH, North KN, Rennke H, Correia LA, et al. (2000) Mutations in ACTN4, encoding alpha-actinin-4, cause familial focal segmental glomerulosclerosis. Nat Genet 24: 251-256.

7. Boute N, Gribouval O, Roselli S, Benessy F, Lee H, et al. (2000) NPHS2, encoding the glomerular protein podocin, is mutated in autosomal recessive steroid-resistant nephrotic syndrome. Nat Genet 24: 349-354.

8. Reiser J, Polu KR, Möller CC, Kenlan P, Altintas MM, et al. (2005) TRPC6 is a glomerular slit diaphragm-associated channel required for normal renal function. Nat Genet 37: 739-744.

9. Winn MP, Conlon PJ, Lynn KL, Farrington MK, Creazzo T, et al. (2005) A mutation in the TRPC6 cation channel causes familial focal segmental glomerulosclerosis. Science 308: 1801-1804.

10. Donoviel DB, Freed DD, Vogel H, Potter DG, Hawkins E, et al. (2001) Proteinuria and perinatal lethality in mice lacking NEPH1, a novel protein with homology to NEPHRIN. Mol Cell Biol 21: 4829-4836.

11. Hinkes B, Wiggins RC, Gbadegesin R, Vlangos CN, Seelow D, et al. (2006) Positional cloning uncovers mutations in PLCE1 responsible for a nephrotic syndrome variant that may be reversible. Nat Genet 38: 1397-1405

12. Brown EJ, Schlöndorff JS, Becker DJ, Tsukaguchi H, Tonna SJ, et al. (2010) 
Citation: Meliambro K, He JC, Campbell KN (2013) The Podocyte as a Therapeutic Target in Proteinuric Kidney Disease. J Nephrol Ther 3: 143. doi:10.4172/2161-0959.1000143

Page 5 of 7

Mutations in the formin gene INF2 cause focal segmental glomerulosclerosis. Nat Genet 42: 72-76.

13. Barua M, Brown EJ, Charoonratana VT, Genovese G, Sun H, et al. (2013) Mutations in the INF2 gene account for a significant proportion of familial but not sporadic focal and segmental glomerulosclerosis. Kidney Int 83: 316-322.

14. Wharram BL, Goyal M, Wiggins JE, Sanden SK, Hussain S, et al. (2005) Podocyte depletion causes glomerulosclerosis: diphtheria toxin-Â-induced podocyte depletion in rats expressing human diphtheria toxin receptor transgene. J Am Soc Nephrol 16: 2941-2952.

15. Kim YH, Goyal M, Kurnit D, Wharram B, Wiggins J, et al. (2001) Podocyte depletion and glomerulosclerosis have a direct relationship in the PAN-treated rat. Kidney Int 60: 957-968.

16. Pagtalunan ME, Miller PL, Jumping-Eagle S, Nelson RG, Myers BD, et al. (1997) Podocyte loss and progressive glomerular injury in type II diabetes. J Clin Invest 99: 342-348.

17. Steffes MW, Schmidt D, McCrery R, Basgen JM; International Diabetic Nephropathy Study Group (2001) Glomerular cell number in normal subjects and in type 1 diabetic patients. Kidney Int 59: 2104-2113.

18. White KE, Bilous RW, Marshall SM, El Nahas M, Remuzzi G, et al. (2002) Podocyte number in normotensive type 1 diabetic patients with albuminuria. Diabetes 51: 3083-3089.

19. Lemley KV, Lafayette RA, Safai M, Derby G, Blouch K, et al. (2002) Podocytopenia and disease severity in IgA nephropathy. Kidney Int 61: 14751485.

20. Kriz W, Elger M, Nagata M, Kretzler M, Uiker S, et al. (1994) The role of podocytes in the development of glomerular sclerosis. Kidney Int Suppl 45: S64-72.

21. Lewis EJ, Hunsicker LG, Bain RP, Rohde RD (1993) The effect of angiotensinconverting-enzyme inhibition on diabetic nephropathy. The Collaborative Study Group. N Engl J Med 329: 1456-1462.

22. Cao Z, Cooper ME (2001) Role of angiotensin II in tubulointerstitial injury. Semin Nephrol 21: 554-562.

23. Sharma R, Lovell HB, Wiegmann TB, Savin VJ (1992) Vasoactive substances induce cytoskeletal changes in cultured rat glomerular epithelial cells. J Am Soc Nephrol 3: 1131-1138.

24. Macconi D, Ghilardi M, Bonassi ME, Mohamed El, Abbate M, et al. (2000) Effect of angiotensin-converting enzyme inhibition on glomerular basement membrane permeability and distribution of zonula occludens- 1 in MWF rats. J Am Soc Nephrol 11: 477-489.

25. Kelly DJ, Aaltonen P, Cox AJ, Rumble JR, Langham R, et al. (2002) Expression of the slit-Â-diaphragm protein, nephrin, in experimental diabetic nephropathy: differing effects of anti-Â-proteinuric therapies. Nephrology, dialysis, transplantation: official publication of the European Dialysis and Transplant Association European Renal Association 17: 1327-1332.

26. Mifsud SA, Allen TJ, Bertram J F, Hulthen UL, Kelly DJ, et al. (2001) Podocyte foot process broadening in experimental diabetic nephropathy: amelioration with renin-Â-angiotensin blockade. Diabetologia 44: 878-882.

27. Endlich N, Kress KR, Reiser J, Uttenweiler D, Kriz W, et al. (2001) Podocytes respond to mechanical stress in vitro. J Am Soc Nephrol 12: 413-422.

28. Durvasula RV, Petermann AT, Hiromura K, Blonski M, Pippin J, et al. (2004) Activation of a local tissue angiotensin system in podocytes by mechanical strain. Kidney Int 65: 30-39.

29. Durvasula RV, Shankland SJ (2008) Activation of a local renin angiotensin system in podocytes by glucose. Am J Physiol Renal Physiol 294: F830-839.

30. Nitschke R, Henger A, Ricken S, Gloy J, Müller V, et al. (2000) Angiotensin II increases the intracellular calcium activity in podocytes of the intact glomerulus. Kidney Int 57: 41-49.

31. Anderson M, Roshanravan H, Khine J, Dryer SE (2013) Angiotensin II activation of canonical transient receptor potential-6 (TRPC6) channels in rat podocytes requires generation of reactive oxygen species. J Cell Physiol .

32. Saito T, Fukuzawa J, Osaki J, Sakuragi H, Yao N, et al. (2003) Roles of calcineurin and calcium/calmodulin-Â-dependent protein kinase II in pressure overload-Â-induced cardiac hypertrophy. Journal of molecular and cellular cardiology 35: 1153-1160.

33. Finkbeiner S, Tavazoie SF, Maloratsky A, Jacobs KM, Harris KM, et al. (1997)
CREB: a major mediator of neuronal neurotrophin responses. Neuron 19 1031-1047.

34. He W, Kang YS, Dai C, Liu Y (2011) Blockade of Wnt $/ \hat{I}^{2}$-catenin signaling by paricalcitol ameliorates proteinuria and kidney injury. J Am Soc Nephrol 22: 90-103.

35. Palomeque J, Rueda OV, Sapia L, Valverde CA, Salas M, et al. (2009) Angiotensin II-Â-induced oxidative stress resets the $\mathrm{Ca}+$ dependence of $\mathrm{Ca} 2+-\hat{A}$-calmodulin protein kinase II and promotes a death pathway conserved across different species. Circulation research 105: 1204-1212.

36. Jiang L, Xu L, Song Y, Li J, Mao J, et al. (2013) Calmodulin-Â-dependent protein kinase II/cAMP response element-Â-binding protein/Wnt/beta-Âcatenin signaling cascade regulates angiotensin II-Â-induced podocyte injury and albuminuria. The Journal of biological chemistry 288: 23368-23379.

37. Chen J, Chen JK, Nagai K, Plieth D, Tan M, et al. (2012) EGFR signaling promotes TGF ${ }^{2}$-dependent renal fibrosis. J Am Soc Nephrol 23: 215-224.

38. Wang D, Dai C, Li Y, Liu Y (2011) Canonical Wnt $/ /^{2}$-catenin signaling mediates transforming growth factor- $\left.\right|^{2} 1$-driven podocyte injury and proteinuria. Kidney Int 80: 1159-1169.

39. Shalhoub RJ (1974) Pathogenesis of lipoid nephrosis: a disorder of T-cell function. Lancet 2: 556-560.

40. Bakker WW, van Dael CM, Pierik LJ, van Wijk JA, Nauta J, et al. (2005) Altered activity of plasma hemopexin in patients with minimal change disease in relapse. Pediatr Nephrol 20: 1410-1415.

41. Bakker WW, Borghuis T, Harmsen MC, van den Berg A, Kema IP, et al. (2005) Protease activity of plasma hemopexin. Kidney Int 68: 603-610.

42. Clement LC, Avila-Casado C, Macé C, Soria E, Bakker WW, et al. (2011) Podocyte-secreted angiopoietin-like-4 mediates proteinuria in glucocorticoidsensitive nephrotic syndrome. Nat Med 17: 117-122.

43. Lagrue G, Branellec A, Xheneumont S, Hanbec G, Weil B (1975) [Vascular permeability factor in the supernatant of lymphocyte cultures in subjects with nephrotic syndrome]. J Urol Nephrol (Paris) 81: 344-348.

44. McCarthy ET, Sharma M, Savin VJ (2010) Circulating permeability factors in idiopathic nephrotic syndrome and focal segmental glomerulosclerosis. Clin $\mathrm{J}$ Am Soc Nephrol 5: 2115-2121.

45. Wei C, El Hindi S, Li J, Fornoni A, Goes N, et al. (2011) Circulating urokinase receptor as a cause of focal segmental glomerulosclerosis. Nat Med 17: 952 960 .

46. Yan K, Kudo A, Hirano H, Watanabe T, Tasaka T, et al. (1999) Subcellular localization of glucocorticoid receptor protein in the human kidney glomerulus. Kidney Int 56: 65-73.

47. Castellino F, Heuser J, Marchetti S, Bruno B, Luini A (1992) Glucocorticoid stabilization of actin filaments: a possible mechanism for inhibition of corticotropin release. Proc Natl Acad Sci USA 89: 3775-3779.

48. Koukouritaki SB, Lianos EA (1999) Glucocorticoid effect on human mesangial cell cytoskeletal proteins. J Lab Clin Med 133: 378-383.

49. Ransom RF, Lam NG, Hallett MA, Atkinson SJ, Smoyer WE (2005) Glucocorticoids protect and enhance recovery of cultured murine podocytes via actin filament stabilization. Kidney Int 68: 2473-2483.

50. Wada T, Pippin JW, Marshall CB, Griffin SV, Shankland SJ (2005) Dexamethasone prevents podocyte apoptosis induced by puromycin aminonucleoside: role of $\mathrm{p} 53$ and $\mathrm{Bcl}-2$-related family proteins. J Am Soc Nephrol 16: 2615-2625.

51. Banfi G, Colturi C, Montagnino G, Ponticelli C (1990) The recurrence of focal segmental glomerulosclerosis in kidney transplant patients treated with cyclosporine. Transplantation 50: 594-596.

52. Meyrier A, Simon P (1988) Treatment of corticoresistant idiopathic nephrotic syndrome in the adult: minimal change disease and focal segmental glomerulosclerosis. Adv Nephrol Necker Hosp 17: 127-150.

53. Brodehl J (1991) The treatment of minimal change nephrotic syndrome: lessons learned from multicentre co-operative studies. Eur J Pediatr 150: 380-387.

54. Crabtree GR, Olson EN (2002) NFAT signaling: choreographing the social lives of cells. Cell 109 Suppl: S67-79.

55. Meyrier A (2005) Treatment of focal segmental glomerulosclerosis. Expert Opin Pharmacother 6: 1539-1549. 
Citation: Meliambro K, He JC, Campbell KN (2013) The Podocyte as a Therapeutic Target in Proteinuric Kidney Disease. J Nephrol Ther 3: 143. doi:10.4172/2161-0959.1000143

Page 6 of 7

56. Charbit M, Gubler MC, Dechaux M, Gagnadoux MF, Grünfeld JP, et al. (2007) Cyclosporin therapy in patients with Alport syndrome. Pediatr Nephrol 22: 57 63.

57. Asanuma K, Kim K, Oh J, Giardino L, Chabanis S, et al. (2005) Synaptopodin regulates the actin-bundling activity of alpha-actinin in an isoform-specific manner. J Clin Invest 115: 1188-1198.

58. Asanuma K, Yanagida-Asanuma E, Faul C, Tomino Y, Kim K, et al. (2006) Synaptopodin orchestrates actin organization and cell motility via regulation of RhoA signalling. Nat Cell Biol 8: 485-491.

59. Faul C, Donnelly M, Merscher-Gomez S, Chang YH, Franz S, et al. (2008) The actin cytoskeleton of kidney podocytes is a direct target of the antiproteinuric effect of cyclosporine A. Nat Med 14: 931-938.

60. Kuwahara K, Wang Y, McAnally J, Richardson JA, Bassel-Duby R, et al (2006) TRPC6 fulfills a calcineurin signaling circuit during pathologic cardiac remodeling. J Clin Invest 116: 3114-3126.

61. Möller CC, Wei C, Altintas MM, Li J, Greka A, et al. (2007) Induction of TRPC6 channel in acquired forms of proteinuric kidney disease. J Am Soc Nephro 18: $29-36$

62. Cravedi P, Kopp JB, Remuzzi G (2013) Recent progress in the pathophysiology and treatment of FSGS recurrence. Am J Transplant 13: 266-274.

63. Specks U, Merkel PA, Seo P, Spiera R, Langford CA, et al. (2013) Efficacy of remission-Â-induction regimens for ANCA-Â- associated vasculitis. The New England journal of medicine 369: 417-427.

64. Munyentwali H, Bouachi K, Audard V, Remy P, Lang P, et al. (2013) Rituximab is an efficient and safe treatment in adults with steroid-dependent minimal change disease. Kidney Int 83: 511-516.

65. Ravani P, Ponticelli A, Siciliano C, Fornoni A, Magnasco A, et al. (2013) Rituximab is a safe and effective long-Â-term treatment for children with steroid and calcineurin inhibitor-Â-dependent idiopathic nephrotic syndrome. Kidney Int 84: 1025-1033.

66. Perosa F, Favoino E, Caragnano MA, Dammacco F (2006) Generation of biologically active linear and cyclic peptides has revealed a unique fine specificity of rituximab and its possible cross-reactivity with acid sphingomyelinase-like phosphodiesterase 3b precursor. Blood 107: 1070-1077.

67. Bezombes C, Grazide S, Garret C, Fabre C, Quillet-Mary A, et al. (2004) Rituximab antiproliferative effect in B-lymphoma cells is associated with acidsphingomyelinase activation in raft microdomains. Blood 104: 1166-1173.

68. Bollinger CR, Teichgräber V, Gulbins E (2005) Ceramide-enriched membrane domains. Biochim Biophys Acta 1746: 284-294.

69. Fornoni A, Sageshima J, Wei C, Merscher-Â-Gomez S, Aguillon-Â-Prada $R$, et al. (2011) Rituximab targets podocytes in recurrent focal segmental glomerulosclerosis. Science translational medicine 3: 85ra46.

70. Rosenmann E, Aviram A (1973) Glomerular involvement in storage diseases. J Pathol 111: 61-64.

71. Barisoni L, Kriz W, Mundel P, D'Agati V (1999) The dysregulated podocyte phenotype: a novel concept in the pathogenesis of collapsing idiopathic focal segmental glomerulosclerosis and HIV-Â-associated nephropathy. Journal of the American Society of Nephrology 10: 51-61.

72. Schwartz EJ, Cara A, Snoeck H, Ross MD, Sunamoto M, et al. (2001) Human immunodeficiency virus-1 induces loss of contact inhibition in podocytes. $\mathrm{J}$ Am Soc Nephrol 12: 1677-1684.

73. Husain M, Gusella GL, Klotman ME, Gelman IH, Ross MD, et al. (2002) HIV-1 Nef induces proliferation and anchorage-independent growth in podocytes. $J$ Am Soc Nephrol 13: 1806-1815.

74. Sunamoto M, Husain M, He JC, Schwartz EJ, Klotman PE (2003) Critical role for Nef in HIV-1-induced podocyte dedifferentiation. Kidney Int 64: 1695-1701.

75. He JC, Husain M, Sunamoto M, D'Agati VD, Klotman ME, et al. (2004) Ne stimulates proliferation of glomerular podocytes through activation of Srcdependent Stat3 and MAPK1,2 pathways. J Clin Invest 114: 643-651.

76. Napoli JL, Race KR (1987) The biosynthesis of retinoic acid from retinol by rat tissues in vitro. Arch Biochem Biophys 255: 95-101.

77. Evans TR, Kaye SB (1999) Retinoids: present role and future potential. Br J Cancer 80: 1-8.

78. Hong HY, Varvayanis S, Yen A (2001) Retinoic acid causes MEK-dependent
RAF phosphorylation through RARalpha plus RXR activation in HL-60 cells Differentiation 68: 55-66.

79. Radominska-Pandya A, Chen G, Czernik PJ, Little JM, Samokyszyn VM, et al (2000) Direct interaction of all-trans-retinoic acid with protein kinase C (PKC) Implications for PKC signaling and cancer therapy. J Biol Chem 275: 2232422330.

80. Wagner J, Dechow C, Morath C, Lehrke I, Amann K, et al. (2000) Retinoic acid reduces glomerular injury in a rat model of glomerular damage. J Am Soc Nephrol 11: 1479-1487.

81. Suzuki A, Ito T, Imai E, Yamato M, Iwatani H, et al. (2003) Retinoids regulate the repairing process of the podocytes in puromycin aminonucleoside-induced nephrotic rats. J Am Soc Nephrol 14: 981-991.

82. Pérez de Lema G, Lucio-Cazaña FJ, Molina A, Luckow B, Schmid H, et al. (2004) Retinoic acid treatment protects MRL/lpr lupus mice from the development of glomerular disease. Kidney Int 66: 1018-1028.

83. He JC, Lu TC, Fleet M, Sunamoto M, Husain M, et al. (2007) Retinoic acid inhibits HIV-1-induced podocyte proliferation through the CAMP pathway. J Am Soc Nephrol 18: 93-102.

84. Endlich N, Endlich K (2002) cAMP pathway in podocytes. Microsc Res Tech 57: 228-231.

85. Larson RS, Tallman MS (2003) Retinoic acid syndrome: manifestations pathogenesis, and treatment. Best Pract Res Clin Haematol 16: 453-461.

86. Ratnam KK, Feng X, Chuang PY, Verma V, Lu TC, et al. (2011) Role of the retinoic acid receptor-Ît in HIV-associated nephropathy. Kidney Int 79: 624634

87. Lu Y, Bertran S, Samuels TA, Mira-Â-y-Â-Lopez R, Farias EF (2010) Mechanism of inhibition of MMTV-Â-neu and MMTV-Â-wnt1 induced mammary oncogenesis by RARalpha agonist AM580. Oncogene 29: 3665-3676.

88. Zhong Y, Wu Y, Liu R, Li Z, Chen Y, et al. (2011) Novel retinoic acid receptor alpha agonists for treatment of kidney disease. PLoS One 6: e27945.

89. Michalik L, Auwerx J, Berger JP, Chatterjee VK, Glass CK, et al. (2006) International Union of Pharmacology. LXI. Peroxisome proliferator-Â-activated receptors. Pharmacological reviews 58: 726-741.

90. Yang HC, Deleuze S, Zuo Y, Potthoff SA, Ma LJ, et al. (2009) The PPARgamma agonist pioglitazone ameliorates aging-related progressive renal injury. $\mathrm{J} A m$ Soc Nephrol 20: 2380-2388.

1. Cha DR, Zhang X, Zhang Y, Wu J, Su D, et al. (2007) Peroxisome proliferator activated receptor alpha/gamma dual agonist tesaglitazar attenuates diabetic nephropathy in db/db mice. Diabetes 56: 2036-2045.

92. Sarafidis PA, Stafylas PC, Georgianos PI, Saratzis AN, Lasaridis AN (2010) Effect of thiazolidinediones on albuminuria and proteinuria in diabetes: a metaanalysis. Am J Kidney Dis 55: 835-847.

93. Yang HC, Ma LJ, Ma J, Fogo AB (2006) Peroxisome proliferator-activated receptor-gamma agonist is protective in podocyte injury-associated sclerosis. Kidney Int 69: 1756-1764.

94. Kanjanabuch T, Ma LJ, Chen J, Pozzi A, Guan Y, et al. (2007) PPAR-gamma agonist protects podocytes from injury. Kidney Int 71: 1232-1239.

95. Liu HF, Guo LQ, Huang YY, Chen K, Tao JL, et al. (2010) Thiazolidinedione attenuate proteinuria and glomerulosclerosis in Adriamycin-induced nephropathy rats via slit diaphragm protection. Nephrology (Carlton) 15: 75-83.

96. Agrawal S, Guess AJ, Benndorf R, Smoyer WE (2011) Comparison of direct action of thiazolidinediones and glucocorticoids on renal podocytes: protection from injury and molecular effects. Mol Pharmacol 80: 389-399.

97. Grande MT Lopez-Â-Novoa JM (2008) Therapeutical relevance of MAP Â-kinase inhibitors in renal diseases: current knowledge and future clinical perspectives. Current medicinal chemistry 15: 2054-2070.

98. Dores RM (2009) Adrenocorticotropic hormone, melanocyte-stimulating hormone, and the melanocortin receptors: revisiting the work of Robert Schwyzer: a thirty-year retrospective. Ann N Y Acad Sci 1163: 93-100.

99. Pachioli R, Genova R (1971) Long-term steroid-immunosuppressive treatment of the childhood nephrotic syndrome. Pediatrics 47: 731-736.

100. Berg AL, Nilsson-Ehle P, Arnadottir M (1999) Beneficial effects of ACTH on the serum lipoprotein profile and glomerular function in patients with membranous nephropathy. Kidney Int 56: 1534-1543. 
Citation: Meliambro K, He JC, Campbell KN (2013) The Podocyte as a Therapeutic Target in Proteinuric Kidney Disease. J Nephrol Ther 3: 143. doi:10.4172/2161-0959.1000143

101.Ponticelli C, Passerini P, Salvadori M, Manno C, Viola BF, et al. (2006) A randomized pilot trial comparing methylprednisolone plus a cytotoxic agent versus synthetic adrenocorticotropic hormone in idiopathic membranous nephropathy. Am J Kidney Dis 47: 233-240.

102.Berg AL, Arnadottir M (2004) ACTH-induced improvement in the nephrotic syndrome in patients with a variety of diagnoses. Nephrol Dial Transplant 19: 1305-1307.

103.Lindskog A, Ebefors K, Johansson ME, Stefánsson B, Granqvist A, et al. (2010) Melanocortin 1 receptor agonists reduce proteinuria. J Am Soc Nephrol 21: $1290-1298$.
104. Scott DL, Wolfe F, Huizinga TW (2010) Rheumatoid arthritis. Lancet 376 : 1094-1108.

105. Reiser J, von Gersdorff G, Loos M, Oh J, Asanuma K, et al. (2004) Induction of B7-1 in podocytes is associated with nephrotic syndrome. J Clin Invest 113 1390-1397.

106. Yu CC, Fornoni A, Weins A, Hakroush S, Maiaguel D, et al. (2013) Abatacept in B7-1-Positive Proteinuric Kidney Disease. N Engl J Med. 